\title{
Metallographic Techniques and Analysis of Nitinol Alloys
}

\author{
Scott Lieberman, Brad James
}

Exponent Failure Analysis Associates. New York, New York 10170 USA

Widespread use of nickel-titanium (nitinol) alloy materials in the medical device industry has created a substantial need for metallographic analysis to be used for a variety of applications, including failure analysis, process development (such as refinement of electropolishing procedures), and quality control. Of particular need is a technique that will consistently allow for the accurate characterization of microstructural features in superelastic nitinol alloys used in medical device applications that are austenitic at room temperature.

Multiple metallographic studies of superelastic nitinol alloys using acid etchants have observed a "needle-like", or acicular microstructure [1-4]. We have confirmed this effect with etchants using nitric, acetic, and hydrofluoric acids when applied to the polished surface of nominally austenitic superelastic nitinol metallographic specimens, as shown in Figure 1.

Tint etchants are reagent solutions that, upon immersion of a metallographic sample, deposit a thin oxide or sulfide film that produces selective color contrast under bright field illumination as well as with polarized light, in most cases without actually etching the underlying surface [5]. A tint etching technique developed and refined for examination of superelastic nitinol alloys used in medical device applications has enabled the analysis of a variety of microstructural features, including grain size, weld penetration, and heat affected zones (HAZ).

A polished and tint etched metallographic cross-section of a superelastic nitinol alloy specimen is shown in Figure 2. Using this technique, the grain size of the austenitic phase can be observed.

Nitinol wires are commonly laser-welded together in certain implantable devices, and weld defects such as misalignment, insufficient weld penetration, and excessive HAZ can affect the service life of the component. Metallographic analysis of welded specimens has been used to refine and verify the parameters used in the laser welding process, with an example shown in Figure 3. The extent of the weld penetration and HAZ are clearly seen.

A conventional method for production of many nitinol devices involves laser-cutting a pattern from a solid tube. The resultant HAZ on the cut surfaces must be subsequently removed, typically by an electropolishing procedure. Nitinol metallography has assisted in refining the electropolishing process to ensure complete HAZ removal. Figure 4 shows a narrow re-melted zone evidenced by columnar grains less than $1 \mu \mathrm{m}$ in width and approximately $20-30 \mu \mathrm{m}$ in depth that was created by the heat from laser cutting.

\section{References:}

[1] A Undisz, K Reuther, H Reuther, and M Rettenmayr, "Occurrence and origin of non-martensitic acicular artifacts on NiTi," Acta Materialia 59, 1 (2011), pp. 216-224.

[2] A Undisz, M Rettenmayr, M Wilke, L Spieß, "Non-martensitic Needle-like Structures on Ni-Ti Alloys - Occurrence and Origin," ESOMAT 2009, 02034 (2009). 
[3] GF Vander Voort, "Specimen preparation for metallographic examination of medical devices," Advanced Materials \& Processes 167, 4 (2009), p. 51.

[4] JM Gallardo, EJ Herrera, P Guempel, J Strittmatter, "Metallographic Characterization of a NiTiCu shape memory alloy," Praktische Metallographie 36, 11 (1999), pp. 594-608.

[5] GF Vander Voort, Metallography: Principles and Practice ASM International (2007), pp. 174-177.
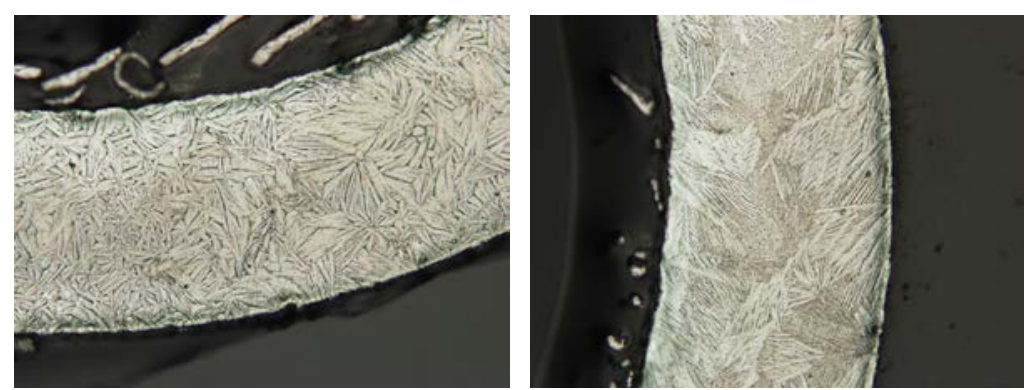

Fig. 1. Metallographic images of an acid-etched superelastic nitinol specimen, showing an acicular microstructure.
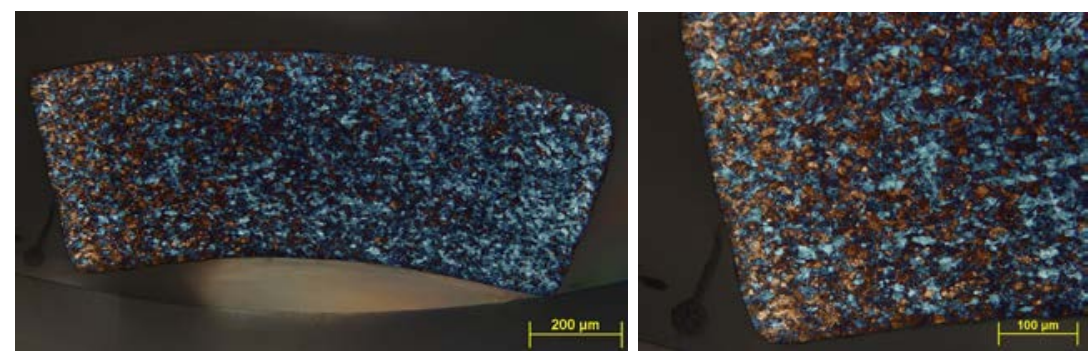

Fig.2. Metallographic images of a superelastic nitinol alloy specimen, with individual grains clearly visualized by the tint etch.
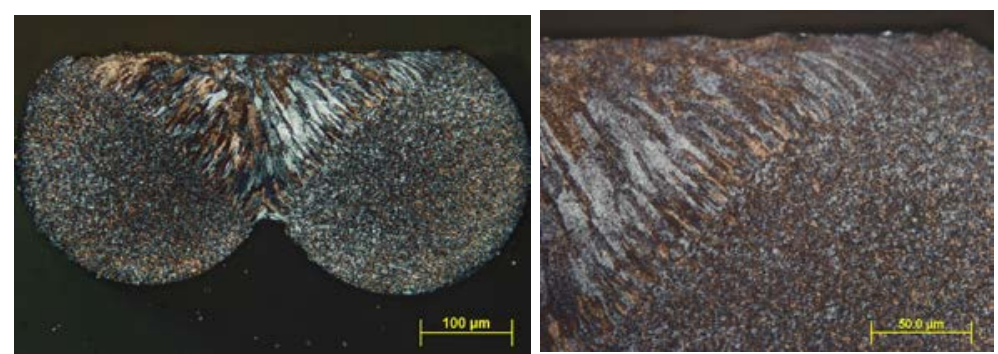

Fig. 3. Metallographic images of a laser-welded superelastic nitinol alloy specimen.
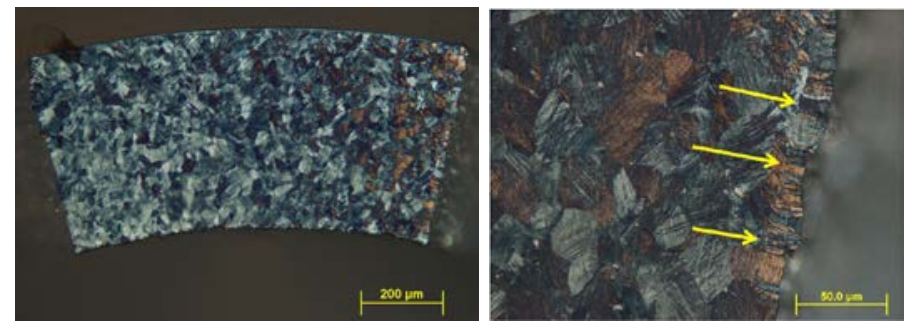

Fig. 4. Metallographic images of a superelastic nitinol alloy specimen, showing evidence of re-melt and heat-affected zone (HAZ) created by laser cutting. The small columnar grains of the HAZ layer are indicated by arrows in the right image. 